\title{
The Need of Linking Local Community and National Disaster Risk Reduction Strategies for Effective Disaster Mitigation: Lessons from Zimbabwe
}

\author{
Elliott P. Niboye ${ }^{1}$ Ngwaru Farai ${ }^{2}$ \\ 1. Institute of Development Studies, University of Dar es Salaam, Mwl Nyerere Main Campus, P.O. Box \\ 35169, Dar es Salaam, Tanzania \\ 2. PhD Candidate, University of Dar es Salaam, Tanzania \\ * E-mail of the corresponding author: epniboye@udsm.ac.tz
}

\begin{abstract}
This article exposes the perceptions of Mhondoro-Ngezi rural communities regarding the contribution of strengthening local community and national disaster risk reduction strategies in mitigating disasters in their district. It further shows the importance and level of community participation in disaster risk reduction programmes and the need for enhancement of community participation in disaster risk reduction (DRR) initiatives. The study utilized both quantitative and qualitative research methodologies in data collection. Data was collected using closed and open ended questionnaires administered to 176 members of the households from a district population of about 102350. Structured interviews were conducted with eight (8) key informants to provide more detailed information. Furthermore, two focus group discussions were conducted to augment what was obtained from the interviews. Community participation was found empowering as social and human capital could be enhanced. Communities were aware that through community participation, they could develop some skills that were necessary for their everyday lives. They could enhance their leadership skills, thereby boosting their livelihoods by working together in community development initiatives. This article recommends that communities need to be engaged so that they become active participants in community DRR interventions. It further recommends that the government should come up with a policy to ensure that DRR activities become participatory at all levels of government administrative tiers. It is also imperative that the government should help communities develop local mechanisms for sustainable disaster risk reduction initiatives.
\end{abstract}

Keywords: Disaster risk reduction, Livelihoods, Participation, Vulnerability, Rural communities

DOI: $10.7176 /$ RHSS/10-2-09

Publication date: January $31^{\text {st }} 2020$

\section{Introduction}

Natural hazards are serious threats to the welfare of individuals, families and communities. The ultimate impact of natural hazards on households and communities depend on the vulnerability of the affected populations (English et al., 2016). The level of effects of a natural hazard to community will be consonant with the disaster mitigation framework that the government has, as well as the relationship and connectedness existing between the local community and its local or central governments in terms of disaster risk reduction (DRR) strategies (Boscarino, 2015). A resilient rural community will have a robust integration of community and national disaster risk reduction strategies and infrastructure for effective and sustainable livelihoods.

It is not feasible for local communities to completely deal with disasters due to a number of reasons like incapacitation. Governments have a crucial responsibility to create environments in which local communities are engaged and empowered to prevent or reduce disaster risks (Scott et al., 2011). They should endeavour to engage in adequate and serious partnerships with local communities and regard them as important stakeholders to disaster preparedness activities (Aldrich et al., 2014). It is has been noted that some rural communities in Southern Africa have inadequate strategies, resources as well as competencies to execute DRR responsibilities (Bongo, 2010). Nevertheless, though rural communities are economically vulnerable, they however have social capital to cope with natural hazards and those are among the greatest assets in disaster risk management (Hossain, 2013).

The central governments and rural communities have a significant role to play in as far as DRR strategies and livelihood improvements are concerned (Malalgoda et al., 2010).It is therefore crucial to integrate community and national disaster risk reduction strategies and best practices into policy making for sustainable DRR and livelihoods. This would enable communities to be able to effectively safeguard and minimize their disaster risks. Twigg (2004) notes that most DRR initiatives fail to achieve key objectives because the role players (local communities and central government) involved in DRR initiatives often work in isolation. Shaw et al. (2011) concurs that DRR strategies are more effective when they involve participation of all actors at all levels starting 
from household, local community, district and regional to national levels. Livingstone (2013) further points out that disaster risk reduction measures are most successful when relevant planning and decision-making involve direct participation of people that are most exposed to hazards. In Zimbabwe, for example, lack of proper synergy between government DRR strategies and those of local communities has led to about 4 million people, including 1.9 million children in rural areas to be at risk of food insecurity leading to acute malnutrition (Benn, 2016). It is without doubt that strengthening community and national DRR strategies has a strong and positive impact on livelihood assets, leading to outcomes of increased resilience, improved food security and stronger society (De Waal, 2015).

Governments should endeavour to capacitate local communities to own grassroots strategies since they are the ones which are normally most affected when emergencies occur (Agrawal, 2015). If the governments make rural community livelihoods stronger and more sustainable, disasters will have less serious negative effects than in situations where weak livelihoods exist (Ndlovu, 2016). They should focus more on engaging communities and empowering them than providing food aid (Flynn et al., (2011). DRR strategies ought to move the nation from reactive approaches to disasters to a proactive stance where communities actively engage in enhancing their own resilience (Carter, 2011). Governments should harness the expertise of rural communities in addressing the locals' vulnerabilities. This could enhance resilience at all levels, especially where local communities actively participate in identifying their challenges as well as formulating strategies for intervention (Bongo et al., 2013). To withstand the effects of natural hazards and to recover, it is crucial that communities and nations should work together (Ndlovu, 2011). A strong and effective national disaster response depends on the synergies between the national government and the activities that take place in the remotest communities.

\section{Theoretical Underpinnings of Disaster Risk Reduction Strategies}

This study is guided by the Sustainable Livelihoods Framework (SLF) propounded by the Department for International Development (DFID). The framework views vulnerability of individuals and populations as emanating from the lack of basic needs in life (Aldrich et al.,2014). The framework specifically focuses on six livelihood assets or capitals which are as follows; natural, human, social, financial, physical and political. The inadequacy of such assets in sustaining acceptable levels of livelihoods is viewed as making a society vulnerable (Patel et al., 2017). The SLF has the view that development begins with the exploitation of available resources to communities which help them achieve better levels of development (Mazibuko, 2013). This is supported by Manyena (2014) who argues that possession of assets or capital in rural areas gives households and communities a more extensive range of options and livelihood opportunities in times of crisis. It can speed up their recovery from different kinds of hazardous events.

From the diagrammatical representation of the SLF below (Figure 2.1), it can be deduced that a community's capitals are influenced by other institutional factors in the social, political, economic and technological environment. The levels of government and private sector involvement affects either positive or negative the laws, policies and cultures that influence the political, social, physical, natural and social capitals. Political capital is viewed by De Bono (2005) as a form of power that politicians can use to exploit and manipulate the public so that they support certain political issues or positions. According to Musevenzi (2012) political capital is one of the most important asset that helps in building sustainable livelihoods. Conversely, the same influence may also be one of the key constraining factors against the achievement of sustainable livelihoods. It has been demonstrated in the SLF that political capital is key to the quality of life communities and families will attain. The downside of the view is that poor politics can expose communities to high levels of vulnerability to natural hazards. 


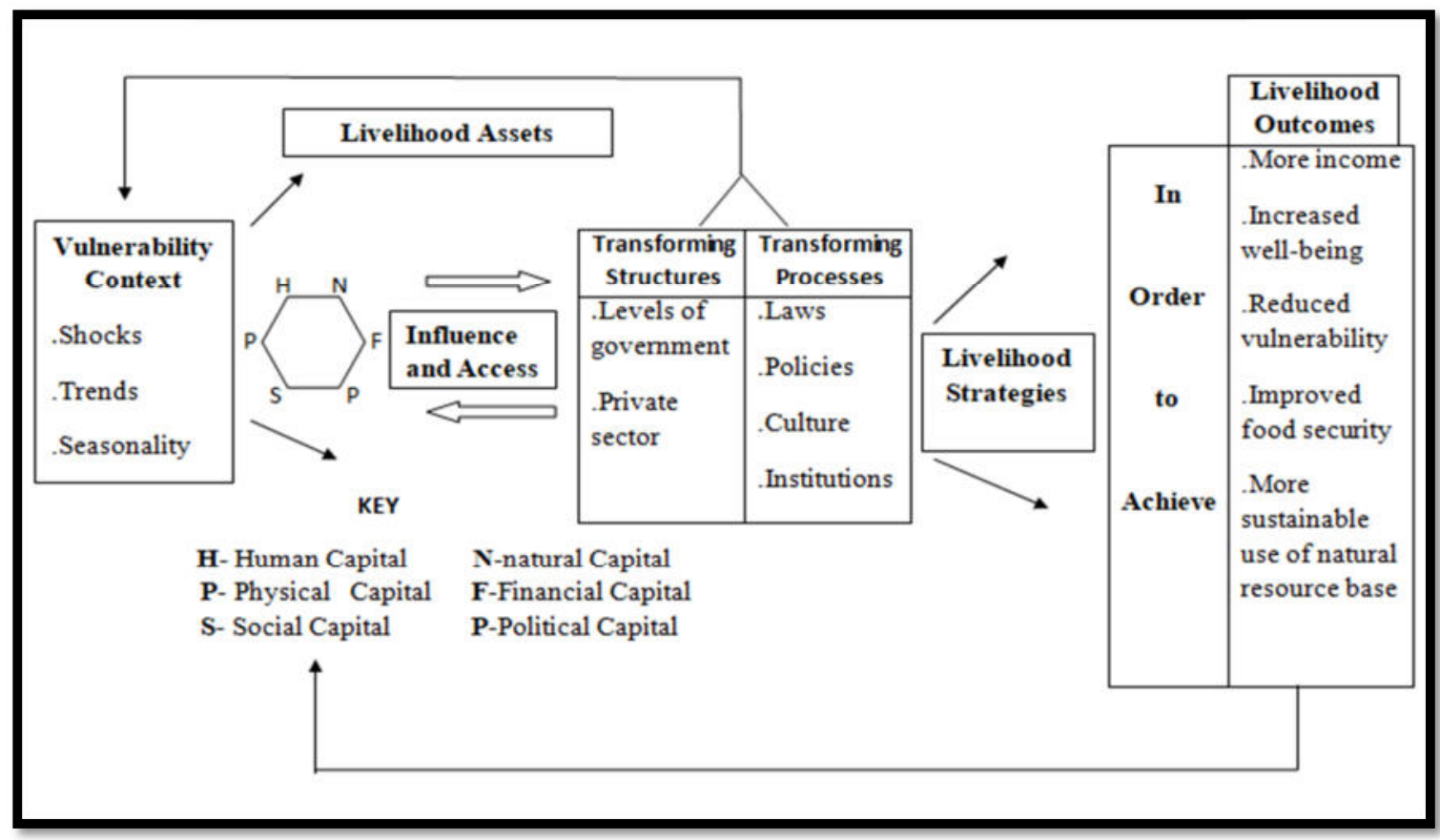

Figure 2.1: Sustainable Livelihoods Framework

Source: Modified from DFID (2004)

The Sustainable Livelihoods Framework is suitable for this study because it is participatory and all inclusive (Hammond, 2010). Accordingly, due to its call for cooperation and participation of all members of the community and government, the SLF affords opportunities for communities to come together and combine their skills and other assets to form a cauldron of support for all their needs. This helps them to build on their resilience in the face of disasters or crisis. It strives to examine and comprehend the developments and dynamics of livelihood approaches and strategies based on the opportunities and assets available within the framework of established pertinent external and institutional environment (Shaw et al., 2011).

The SLF is viewed as bottom up and encourages dialogue and participation of the citizens in decisions that affect them in the short and long run. In addition, the model has the capacity to develop micro -links which make the most marginalised member of society become the focus of attention (De Stage et al., 2002). The application of the SLF approach is flexible and adaptable to specific local settings and to objectives defined in the participatory manner. Its strong focus on the processes of negotiation that take place within local and non-local institutions to mediate access to resources makes SLF useful for analysing how households in Mhondoro-Ngezi engage each other especially in the face of common problems such as droughts and floods.

\section{Methodology and the Justification for the Study Area}

This article is based on a study that was carried out in Mhondoro-Ngezi District, in Mashonaland West Province of Zimbabwe. The district covers about 9327.41 square kilometres, with a population of around 104,342 (Zimstat, 2016). The district has 16 wards with approximately 23,630 households (Zimbabwe National Statistics Agency, 2015). One hundred and seventy six (176) respondents (11 respondents from each of the 16 wards) were randomly selected. Questionnaires were administered in person to research participants. Personal attributes like the representativeness relative to society were considered in judging suitable participants for focus group discussions (FGDs). The participants were drawn from traditional, religious and community leadership, traditional healers and representatives of non-governmental organizations working in the district. A total of 2 FGDs each comprising 8 members was carried out. In addition, 8 key informant interviewees were selected based on their positions in the community or district and having attributes that might come from direct experience or the nature of from their duties in the constituency. A snowballing procedure was utilized to locate the key informants.

Mhondoro-Ngezi District falls under natural region 3 which is characterised by annual rainfalls of 500-750 millimetres (Food and Agricultural Organisation, 2017). The district has witnessed many fluctuating rainy seasons, prolonged mid-season dry spells and sporadic droughts (Madamombe, 2014). The Mhondoro-Ngezi communities depend on subsistence farming which is susceptible to drought and floods. These natural calamities are the major drivers of food insecurities in Mhondoro-Ngezi District (Mashizha et al., 2017). Figure 3.1 shows the Mhondoro- 
Ngezi District, its wards and its location in Zimbabwe.

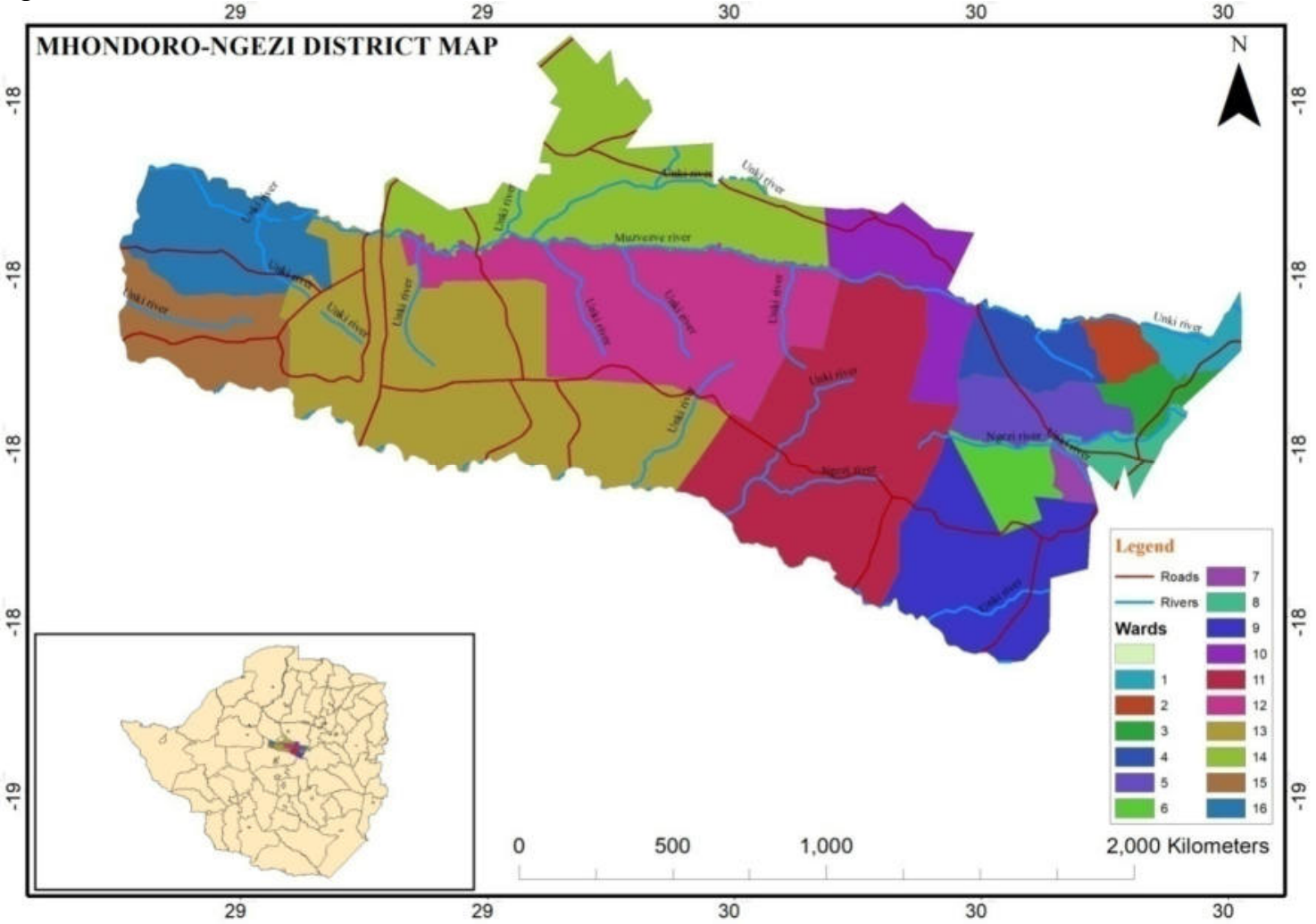

Figure 3.1: Map of Mhondoro-Ngezi District Showing Various Wards

Source: University of Dar es Salaam Cartographic Unit (2017)

The recurrent unfavourable weather conditions in Mhondoro-Ngezi have often caused extensive loss of livestock, crop failure and starvation of people. Floods for example, have caused havoc in the area, with households losing livelihoods and buildings (Madamombe, 2014). The study focused on Mhondoro-Ngezi District because it was anticipated that due to severe weather fluctuations such as floods and droughts, the Zimbabwean Government would intensify the need to enhance its DRR interventions in the region. This is premised on the fact that due to persistent susceptibility of the rural communities to natural calamities, it is plausible that the Zimbabwean Government should engage them in order to improve their livelihoods.

\section{Findings}

The findings of this study are presented in three sub-sections. The first section dwells on the importance of community participation in disaster risk reduction strategies according to the views of research participants, the second section presents the level of community participation in disaster risk reduction programmes and finally the last section looks at the need for enhancement of community participation.

\subsection{Importance of Community Participation in Disaster Risk Reduction Initiatives}

Interviews with key informants reveal that community participation was a way through which individuals could form meaningful relationships with others, and more so, in responding to disasters. The District Environmental Management Agency (DEMA) director asserted that:

"Participation in DRR activities empowers susceptible individuals and communities, making them more self-reliant. It instills a sense of ownership of DRR strategies. This ensures continuity in the implementation of the strategies by individuals and communities. In addition, it reduces individuals and communities' vulnerabilities and enhances their resilience to withstand and recover from stresses and shocks of natural hazards. Participation in DRR initiatives develops individuals and communities' confidence to take part in other community development activities and projects."

It was noted that belonging to a beneficial social circle and to some functional social system was important for the community members. The fact that the population in Mhondoro-Ngezi District was aware that it was beneficial for 
them to take part in DRR programmes could be a positive aspect for future programming. Community participation was instrumental to effective DRR in the area. As such, communities in Mhondoro-Ngezi District were only waiting for the government to engage them in order for DRR activities to be sustainable. This implies that they were ready to participate in projects that are initiated by the government as long as they are involved. Such an approach would have long-term benefits for the people, local and central government. For communities, long-term projects would ensure food security through relevant agricultural technologies coupled with indigenous knowledge. On the other hand, central government will save funds as projects initiated become self-sustaining, thus ensuring food security and resilience by communities.

\subsubsection{Empowering Communities through Participation in DRR Activities}

It was revealed through this study that participating in DRR activities was beneficial for individuals and communities. Majority of the respondents (70.6\%) strongly agreed while 14.5 concurred that in terms of skills, participation in DRR was empowering. Few individuals were ambivalent as to the effect of participating in DRR activities, and extremely few people (3.3\%) were not aware of any benefits that accrued to them as a result of taking part in community projects implemented in their area (Figure 4.1).

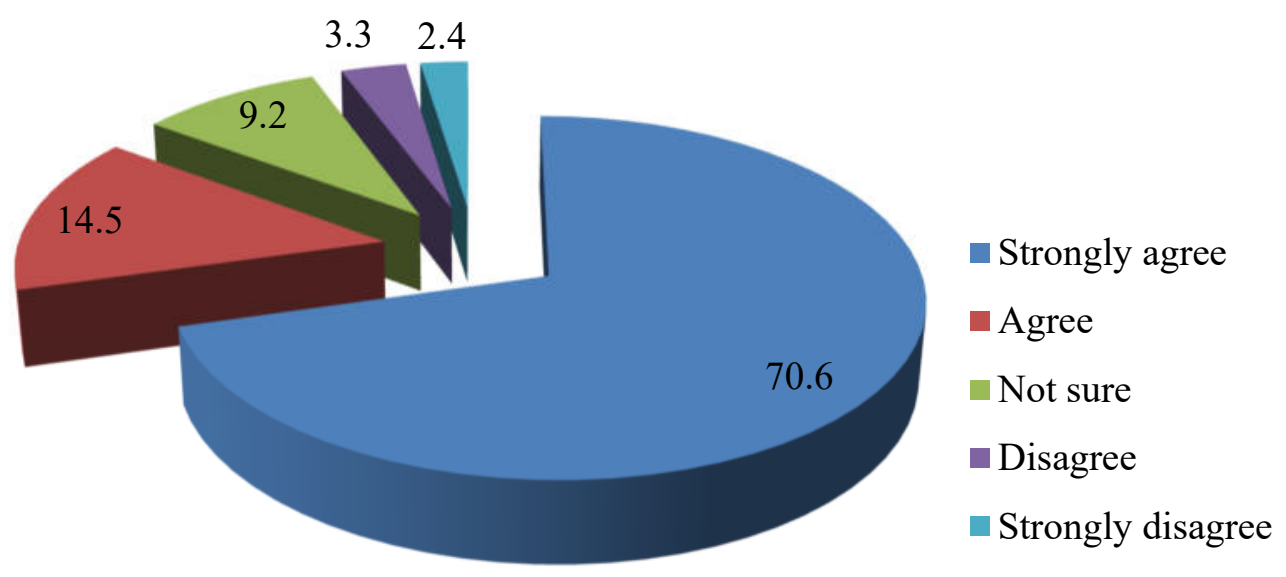

Figure 4.1: $\quad$ Community Participation Empowers Individuals with Skills

Source: Survey Data (2017)

The District Agricultural Technical and Extension Services Department (AGRITEX) director pointed out that:

"Participating in community programming affords members of the community the chance to develop some particular skills. Some of the community members would develop leadership, artisanship and communication skills. In addition, through participation in DRR activities, members of the Mhondoro-Ngezi community would acquire enhanced farming methods and better ways of managing the environment".

This stance is supported by Mashizha et al. (2017) who observed that delegation and taking of responsibilities will ensure that individuals are assigned specific duties within the DRR set up.

\subsubsection{Enhancing Readiness and Resilience through Participation in DRR Programmes}

The majority of respondents $(66.7 \%)$ strongly agreed while $23.4 \%$ concurred that participation in DRR programmes enhanced readiness to any eventuality. Only very few individuals $(6.3 \%)$ could not make a decision as to whether participating in DRR activities contributed to making communities ready and resilient (Figure 4.2). 


\section{Percentage}

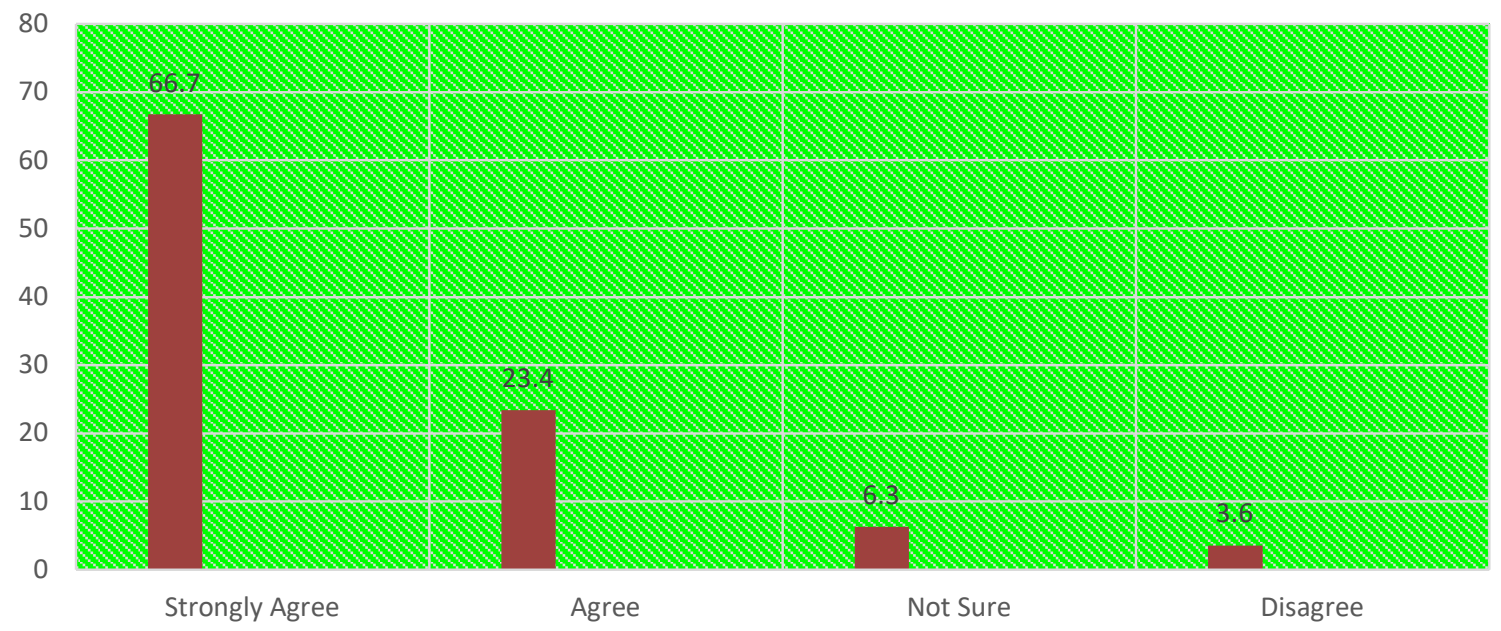

Figure 4.2: Participation in DRR Programmes Enhances Readiness and Resilience

Source: Survey Data (2017).

Some authors support this view by arguing that community participation that includes rehearsals and drills enhance readiness and knowledge of disasters (Akinbami et al., 2016). It further bolsters the skills of rural communities to be ready to respond appropriately in case of a call-out. Besides, community participation helps to identify possible obstacles towards mitigating disasters, especially those emanating from the community practices. Some of the participants in the FGDs noted that DRR programmers were able to appreciate the local culture and resultant belief systems that could either present obstacles or opportunities for DRR programming in Mhondoro-Ngezi District. It was acknowledged that the active participation of the communities in national DRR activities would be very beneficial.

\subsubsection{Encouraging Community Participation}

Local community leaders asserted that one approach that had been used by government and its partners in building infrastructure in Mhondoro-Ngezi District involved the concept of "food for work". Members of the community would provide their labour in a particular activity as a precondition for receiving food aid. This approach was lauded as a sustainable way of ensuring food security in communities because some members of the community did not have money to buy food. The approach provided an alternative way of ensuring that communities were well sustained. Interviews with key informants indicated that the long-term benefits of community participation involved the prevention of diseases related to malnutrition. One of the nurses was quoted saying;

"Women, infants, children and adolescents are all at risk of malnutrition. It affects all age groups. Malnutrition is the major contributor to high mortality due to greater susceptibility to infections and slow recovery from illness. It prevents children from reaching their full physical and mental potential as it causes them to delay in their physical and mental development".

Not only for food benefits, but as some ward councillors put it;

"In addtion to building infrustructres such as roads and brigdes, participating in disaster risk reduction initiatives also enables communities to develop a strong sense of community by working together".

It was found out that the approaches were beneficial for communities in Mhondoro-Ngezi District especially in times of droughts. More importantly, it was a viable project for prevention of disasters. Some authors concur with this approach that the benefits of "food for work" to DRR on recipient communities are that, it encourages communities to choose a strategy of boosting their livelihoods and provide employment (Tinarwo, 2011). It was noted in this study that the approach focused on increasing agricultural production through the teaching of communities on sustainbale farming methods by agricultural extension workers. In addition, food-aid paid in cash was used by members of the communties to buy other food items and even to pay for school fees.

\subsubsection{Community Participation as a Ground for Skills Development}

The majority of the respondents in Mhondoro-Ngezi (71.6\%) had the view that taking part in the community efforts to build resilience against disasters was beneficial in that, it equipped them and their peers with lifelong skills that improved their livelihoods (Figure 4.3). 


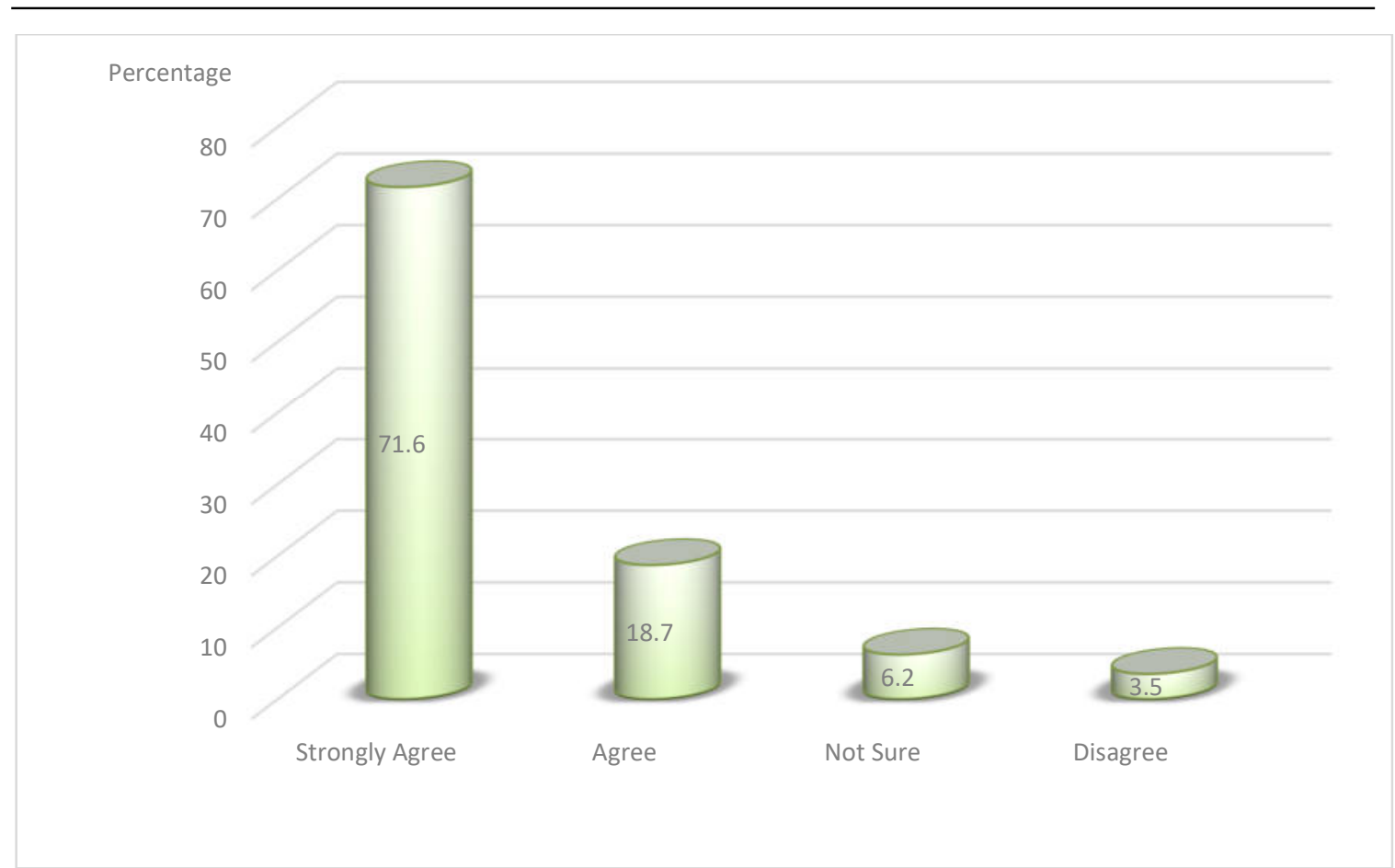

Figure 4.3: Developing Skills through Participation in Disaster Prevention Programmes

Source: Survey Data (2017)

Thus, DRR approaches based on community participation are instrumental for the acquisition of skills that are important for everyday life and even for future personal development such as teamwork and leadership that enhances DRR and livelihoods. It has been established that taking part in community projects not only builds technical skills but also augments the psychological and social capital of families and communities (Luthans et al., 2004; Nath et al., 2013; Shembe, 2015).

It was observed through FGDs that community participation would create employment and preoccupy the youths thereby stopping them from engaging in social ills and vices. Some of the respondents in Mhondoro-Ngezi District believed that employment would improve the livelihoods of communities. One of the school headmasters in the district opined that:

"The young people need to be preoccupied with productive tasks like engaging in farming and none-farming activities, for instance, horticulture and artisanal work respectively. This helps them to avoid the use of illicit drugs which usually reduce their ability to participate in the socio-economic life of their communities".

As such, participation of individuals in community projects indeed helps to improve the livelihoods of communities. Community participation offers opportunities for building political capital through interaction with government and political leaders (De Stage, 2002). Community participation in DRR initiatives would help them build their quality of life thereby reducing their vulnerabilities to disasters. Such an understanding would facilitate and encourage community members to embark on development initiatives that reduce food insecurity in the district. Such insights would serve as the precursor between local community and national programming that encourages participation of all stakeholders in a sustainable way.

\subsubsection{Effects of Strong Social Connections}

Strong social ties often develop when people with common hardships work together. The same is true during the time of disasters and afterwards. This study established that indeed, members of Mhondoro-Ngezi community believed that opportunities for building strong social ties always existed during times of disasters. The District Administrator (DA) had this to say;

"I think people meet and form strong social connections when a disaster occurs.

This enables communities to work together in the future. People in this district have been able to form co-operatives that focus on nutritional gardens. These gardens provide sources of food as well as income".

It has been established that social connections are the bedrock upon which social capital is built (Reininger et al., 2013; Aldrich et al., 2014). Communities in Mhondoro-Ngezi District could utilize this approach if fully supported to enhance their disaster preparedness through improved livelihoods. Examples abound that attest to the success 
of such approaches, for instance, in the low income rural populations in Mexico (Helmore et al., 2001; Reininger et al., 2013). This kind of approach could be utilised to ensure that similar communities in Zimbabwe could benefit from such endeavours. association with the physical processing part of its own or its counterparts under the same holarchy. According to Rodriguez (2005), every holarchy is a moderated group, in which the supra-holon is the representative or moderator of the group as well as a part of the vivid interface in coordination with the local environment; meanwhile, each of the sub-holons has to play at least one role to secure its status in the supra-holon composition.

For the architecture of WOZIP, a holarchy consisting of machinery holon $(\mathrm{MH})$, operational holon $(\mathrm{OH})$, forecasting holon $(\mathrm{FH})$, and sizing holon $(\mathrm{ZH})$ is delineated in Figure 1. The WOZIP is itself regarded as the supraholon, which allows and coordinates the information transfer as well as the interactive computing between the four sub-holons. In the normal process flow, MH (i.e. the order holon) will supply the work information based on customer specifications for $\mathrm{OH}$ (i.e. the resource holon) to prepare the workforce that will handle the machines. At the threshold of workforce sizing, both the $\mathrm{MH}$ and $\mathrm{OH}$, which compose the input holon, will generate their respective data items via Equations (1) to (3), for the use of FH (i.e. the intermediate product holon) to conduct the exponential smoothing. The forecast outcomes of Equation (4) of FH will be channelled into ZH (i.e. the final product holon), which completes the procedure using Equation (5) - adjust the workforce size of OH. Essentially, the $\mathrm{FH}$ and $\mathrm{ZH}$ belong to the output holon. Some negotiation might take place around the beginning and the end of the process flow, between the $\mathrm{MH}$ and the customer side (i.e. the external environment) as well as between the $\mathrm{ZH}$ and the human resources division (i.e. the internal environment). As the whole process will repeat for every production period, a database has to be integrated into each of the holons for efficient information storage and retrieval.

\section{Level of Community Participation in Disaster Risk Reduction Programmes}

In an attempt to establish the level of participation in national DRR by communities in Mhondoro-Ngezi District, the findings were that the majority of respondents (33.4\%) maintained that local communities were not actively involved in national DRR programmes. A further substantial number of respondents $(23.7 \%)$ thought that community participation in DRR programmes was very low. It was also interesting to note that a low number of respondents $(3.5 \%)$ thought that there was very high involvement of communities in DRR activities (Figure 5.1).

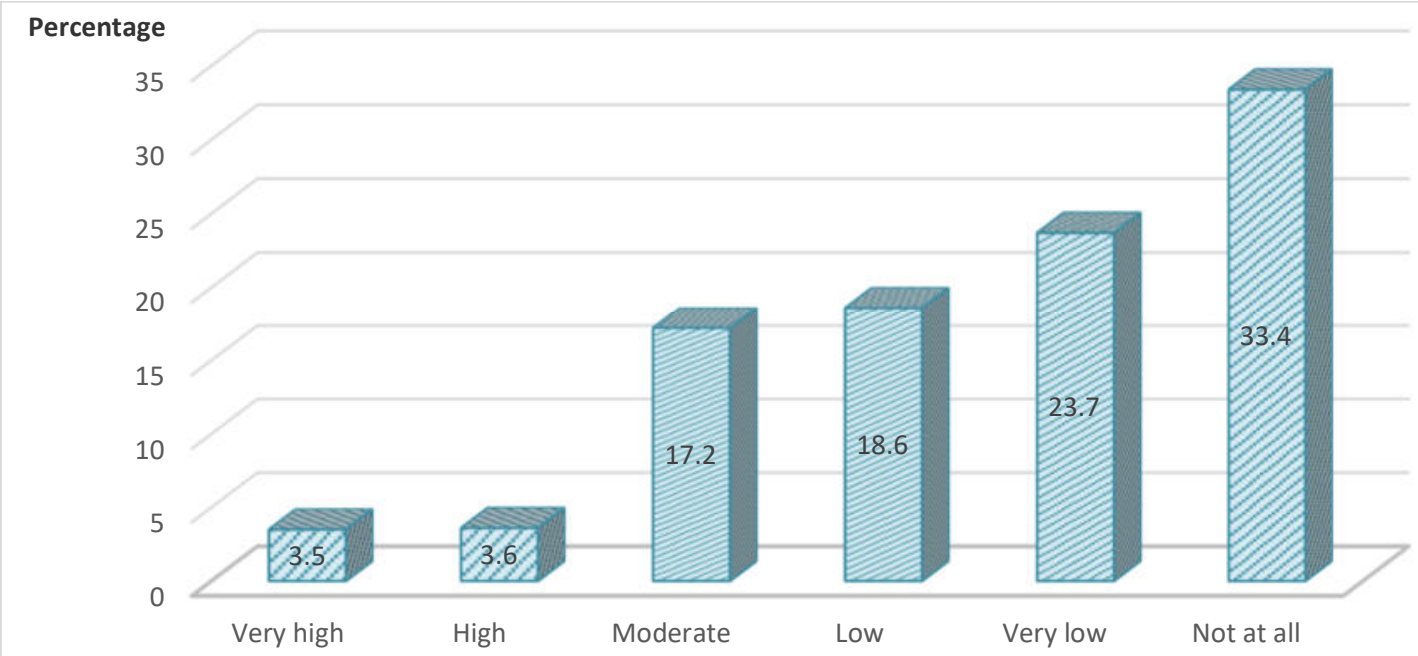

Figure 5.1: Community's Level of Participation in DRR Programmes

Source: Survey Data (2017)

Interviews with community leaders showed that in many cases, communities in Mhondoro-Ngezi District were rarely consulted in DRR and development programming. This would implicitly mean as aptly put by the interview participants, that many of the government agencies and private voluntary organisations just made assumptions about the needs of the communities. This implied that most of the DRR interventions were modelled around passive local participation where the community would simply be told what was going to happen or what had already transpired. Given the foregoing, it is clear that community involvement in national DRR programming 
was lacking, hence, there was no community ownership of the DRR activities in Mhondoro-Ngezi District.

The success of any community intervention is hinged upon the participation of the intended beneficiaries. Fung (2006) strongly advises that if communities are not involved in active participation, they will always see no reason to be worried about the success or failure of the community projects as they would not be accountable in any way whatsoever. These findings have implications to the Zimbabwean Government and its partners as well as Mhondoro-Ngezi communities. Adopting an active participation of local communities in government, DRR activities programming would bring many benefits such as ensuring the success of the DRR activities. It also creates community ownership of such activities for sustained existence and ensuring community cohesion as they work together to execute the DRR activities in their localities.

Community participation allows different perspectives to be heard considering that everyone would be given the opportunity to contribute to a common cause. Participants had the view that learning and skills development would be enhanced and people would be able to assist themselves. Communities would be better placed to assess their own situations, organise themselves as a dominant group and work creatively towards changing society and building up a new community that is able to serve its needs. Lastly, they emphasized that this would increase capacities of individuals, families and groups and allow communities to mobilise and help themselves to minimise dependence on the state in a bottom-up approach. It has been argued that the government of Zimbabwean Government should ensure that resources are availed to communities in a timely manner and that communities have adequate information about hazards in their areas (Mavhura, 2016). This study has revealed that early warning systems were ineffective and DRR activities were reactive due to poor consultation partly caused by low community participation.

\section{Need for Enhancement of Community Participation}

The study established that there was a dire need for the enhancement of community participation as a way of strengthening local communities so as to consolidate the synergy between the community and national DRR strategies. This was aptly put by the local chief who commented that:

"Our communities should be able to work together with the government to improve our yields. If we work together, we could have more yields than when we work as individuals. We need people to work together in cooperatives and get assistance from the government".

The observation by the local chief that communities should work together with the government should have some merit in preventing natural hazards and improving livelihoods in Mhondoro-Ngezi District. Communities working together with the government help to pull resources together. Furthermore, community participation improves relations between members of the community who will then feel that they belong together and have equal stakes in community issues. Such an approach will meet the needs of the poor, the old and those that are physically challenged as they will be able to work with others in the community (United Nations, 2016). It seems that this approach is a missing link between community and national DRR efforts, thus creating disparities between what should be and what really prevails on the ground.

\section{Discussion}

The study revealed that opportunities for the development of leadership and work skills exist during disaster and crisis situations. Many respondents in Mhondoro-Ngezi District were of the opinion that community participation during disasters, apart from yielding more success in disaster response, was a way through which individuals could form meaningful relationships as community participation was consistent with the ideals of $U b u n t u^{l}$. It was noted that participating in community disaster risk programming could help the community members and their families to prepare for natural hazards and enhance their social ties. Since effective DRR depends on political, social and economic capitals (Slocum, 2009; Reininger et al., 2013). Most of the DRR interventions by governments are topdown (Sharma, 2010). This was the situation regarding the programming for DRR in Mhondoro-Ngezi District. It was largely top-down, with very minimum synergy between government and members of the community. This has generated discrepancies between government policies regarding the DRR activities in the district and what actually accrue on the local communities. As Fung (2006) strongly advises that, it is a great disadvantage if communities are not involved in programmes and projects meant to benefit them as they would always feel as if they do not own them, thus see no reason for their sustainability.

\footnotetext{
${ }^{1}$ Ubuntu is a Shona word for humanity/brotherhood, derived from African socialism where people live and share together life experiences
} 
Community participation as an instrument for effective DRR was also viewed as a chance to build associations and connections, thereby enhancing social capital within Mhondoro-Ngezi communities. The study established that Mhondoro-Ngezi communities were aware that they could develop some skills necessary for their everyday lives thus boosting their livelihoods by working together in community development initiatives. Since the communities in Mhondoro-Ngezi District are aware of this possibility, this implies that they are ready to participate in projects that are initiated by the government as long as they are involved. As argued by Skerratt (2013), community participation offers opportunities for building political capital through interaction with government and political leaders. Such an approach would have long-term benefits for the people, local and central government. For communities, long-term projects would ensure food security through relevant agricultural technologies coupled with local knowledge. On the other hand, central government will save funds as projects initiated become selfsustaining, hence, ensuring food security and resilience by communities.

\section{Conclusions and Recommendations}

Since most of the challenges to DRR programming in Mhondoro-Ngezi District were attributed to insufficient government coordination and support, it remains difficult for communities to organize and operationalize those activities alone. This is based on the assumption that programming for DRR remains the responsibility of the government which should then coordinate and engage the activities of local communities in the processes. It was established that Mhondoro-Ngezi communities view community participation as instrumental to effective DRR in their district. As such, they were prepared to be engaged by the government in order for DRR activities to bear fruit.

This paper recommends that the Zimbabwean Government should take advantage of the awareness by the studied communities that participation in DRR enhances personal skills as well as increases social capital; to initiate community based DRR activities. In addition, it should make it a policy that DRR activities adopt a participatory approach, with consultations at all levels of the DRR endeavours. This would ensure that all community members are involved in the development of sustainable strategies for disaster risk reduction. The government support should be in line with the community's needs, so that it would instigate unwarranted hazards. In addition to that, it should endeavour to afford community DRR strategic alternatives that are financially realistic, friendly and viable. Cole (2015) argues that the government support is needed to reinforce local knowledge and capacity.

For community DRR to be strengthened, it is imperative to align it with the national DRR policies and frameworks which must be oriented towards the context and needs of vulnerable communities. This paper further recommends that, the governments should endeavour to create effective channels of communication from the grassroots upwards. Similarly, national policies and plans must cascade down to district and local levels to ensure that they are executed effectively and allow communities to respond to all matters that affect their day to day lives.

\section{References}

Agrawal, A. (2015), Dismantling the Divide between Indigenous and Scientific Knowledge. Development and Change, 26: 413-439.

Akinbami, C. A. O., Ifeanyi-Obi, C., Appiah, D. O. and Kabobah, A. T. (2016), Towards Sustainable Adaptation to Climate Change: The Role of Indigenous Knowledge in Nigeria and Ghana, AJSD, 6(2).

Aldrich, D. P. and Meyer, M. A. (2014), Social Capital and Community Resilience, Journal of American Behavioural Scientist, (254-269).

Baumann, P. (2000), "Sustainable Livelihoods and Political Capital: Arguments and Evidence from Decentralisation and Natural Resource Management in India." ODI Working Paper 136, London: ODI.

Benn, H. (2016), 'We Need an Emergency Service', United Kingdom, DFID.

Bongo, P. P. (2010), Community-Based Disaster Risk Reduction in the Context of Climate Change: The Case of Rural Zimbabwe, Practical Action Southern Africa, Zimbabwe

Bongo, P. P., Chipangura, P., Sithole, M. and Moyo, F. (2013), Dynamics of Configuring and Interpreting the Disaster Risk Script, Experiences from Zimbabwe, Jamba Journal of Disaster Risk Studies, (2-11).

Boscarino, J. A. (2015), Community Disasters, Psychological Trauma and Crisis Intervention. International Journal of Emergency Mental Health, 17(1), (369-371).

Carter, N. (2011), Disaster Management: A Disaster Manager's Handbook. Manila: Asian Development Bank.

Cole, J. (2015), Rural Hazard Risk Communication and Public Education: Strategic and Tactical Best Practices, International Journal of Disaster Risk Reduction, 10, 292-304.

De Bono, E. (2005), Conflicts: A Better Way to Resolve Them, London, Harp Publishers.

De Stage, R. (2002), Learning about Livelihoods. Insights from Southern Africa, Oxford: Oxfam Publishing.

De Waal, A. (2015), Famine Crimes: Politics and the Disaster Relief Industry in Africa. Oxford, Indiana University Press. 
English, P. B. and Richardson, M. J. (2016), Components of Population Vulnerability and their Relationship with Climate-Sensitive Health Threats, Journal of Current Environmental Health Rpt.

Flynn, S. and Bates, S. (2011), Connecting America: Building Resilience with Social Media, Council on Foreign Relations, Washington DC.

Food and Agricultural Organisation. (2017), Zimbabwe's Natural Regions and Farming Systems.

Fung, A. (2006), Varieties of Participation in Complex Governance. Public Administration Review, Volume $66,(66-75)$.

Hammond, W. (2010), Principles of Strength-Based Practice. Resiliency Initiatives, (1-7).

Helmore, G. and Singh, N. (2001), Sustainable Livelihoods: Building on the Wealth of the Poor, Bloomfield, Kumarian Press.

Hossain, A. (2013), Community Participation in Disaster Management: Role of Social Work to Enhance Participation. Journal of Anthropology, 9(1), (159-171

Livingstone, D. (2013), Putting Science in its Place: Geographies of Scientific Knowledge, Chicago, University of Chicago Press.

Luthans, F. Luthans, K. W. and Luthans, B. C. (2004), "Positive Psychological Capital: Beyond Human and Social Capital", London, Management Department Faculty Publications.

Madamombe, E.K. (2014), “Zimbabwe: Flood Management Practices, Selected Flood Prone Areas, Zambezi Basin.” Associated Programme on Flood Management, Harare, Zimbabwe.

Malalgoda, C., Amaratunga, D. and Pathirage, C. (2010), Role of the Local Governments in Disaster Risk Reduction, London, University of Safford.

Manyena, B. (2014), Disaster Resilience: A Question of "Multiple Faces" and "Multiple Spaces"? International Journal of Disaster Risk Reduction, (1-9).

Mashizha, T. M., Monga, N. and Dzvimbo, M. A. (2017), Improving Livelihoods of Resettled Farmers through Development of a Knowledge Base on Climate Change in Mhondoro - Ngezi District, Zimbabwe. International Journal of Sustainable Development Research, 3(2), (18-26).

Mavhura, E., (2016), Disaster Legislation: A Critical Review of the Civil Protection Act of Zimbabwe. National Hazards, Volume 80, (605-621).

Mazibuko, S. (2013), 'Understanding Underdevelopment through the Sustainable Livelihoods Approach', Community Development, 44(2), pp. 173-186.

Musevenzi, J. (2012), Diversification and Improvement of Rural Livelihoods in Semi-Arid Districts of Zimbabwe under Politically Charged Conditions during the Period between 2000 and 2010, Nelson Mandela University, South Africa.

Nath, V., Kumar, R., Agrawal, R., Gautam, A. and Sharma, V. (2013), Consumer Adoption of Green Products: Modelling the Enablers, London, Sage Publications.

Ndlovu, B. (2011), Drought Copying Strategies at Mutasa District in Zimbabwe, Unpublished Masters' Thesis, University of the Free State, South Africa.

Ndlovu, I. (2016), Marginal Identities, Histories and Negotiating Spaces: Life Experiences of Street Children in Bulawayo, Zimbabwe, African Journal of Social Work, Volume 6 Number 2, 2016.

Patel, S. S., Rogers, M. B., Amlot, R. and Rubin, G. J. (2017), What Do We Mean by 'Community Resilience'? A Systematic Literature Review of how it is Defined in the Literature. PLOS Currents Disasters, Volume Edition 1.

Reininger, B. M. (2013), Social Capital and Disaster Preparedness among Low Income Mexican Americans in a Disaster Prone Area, Social Science and Medicine, Volume 83, (50-60).

Scott, Z. and Tarazona, M. (2011), Study on Disaster Risk Reduction, Decentralization and Political Economy, Global Assessment Report on Risk Reduction.

Sharma, A. (2010), Early Warning: Community Interpretations and Perceptions, a Case of Recurrent Floods and their Warnings in Delhi, India.

Shaw, R. (2013), Community Based Disaster Risk Reduction. Bingley, Emerald Publishers.

Shaw, R.Y., Takeuchi, Q.R., Gwee K. and Shiwaku, K. (2011), Disaster Education: An Introduction, Community Environment, Disaster risk management, 7, (1-22).

Shembe, C. (2015), Community Participation in the Zimbabwe Community Development Association (ZCDA) ISAL Project: A Development Communication Perspective. KwaZulu Natal, South Africa.

Skerratt, S. (2013), Enhancing the Analysis of Rural Community Resilience: Evidence from Community Land Ownership. Rural Studies, 31(0), (36-46).

Slocum, R. (2009), Power, Process and Participation: Tools for Change, London, Regal Books.

Tinarwo, C. (2011), An Assessment of the Contribution of Food Aid Programs to Household Food Security 
of Smallholder Farmers in Buhera District, Zimbabwe, Gweru, Unpublished Masters' Thesis.

Twigg, J. (2004), Disaster Risk Reduction: Mitigation and Preparedness in Development and Emergency Programming. Good Practice Review No 9, London.

United Nations, (2016), Disability-Inclusive Disaster Risk Reduction and Emergency Situations, United Nations Division for Social Policy and Development Disability.

Zimbabwe National Statistics Agency, (2015), Women and Men in Zimbabwe Report, Harare: Zim Stat.

Zimstat, (2016), Harare, Government of Zimbabwe.

Twigg, J. (2004), Disaster Risk Reduction: Mitigation and Preparedness in Development and Emergency Programming. Good Practice Review No 9, London.

United Nations, (2016), Disability-Inclusive Disaster Risk Reduction and Emergency Situations, United Nations Division for Social Policy and Development Disability.

Zimbabwe National Statistics Agency, (2015), Women and Men in Zimbabwe Report, Harare: Zim Stat.

Zimstat, (2016), Harare, Government of Zimbabwe. 